\title{
Mariusz Wesołowski
}

Ppłk dr inż.

Instytut Techniczny Wojsk Lotniczych, Warszawa, Zakład Lotniskowy

mariusz.wesolowski@itwl.pl

\section{Krzysztof Blacha}

Mjr mgr inż.

Instytut Techniczny Wojsk Lotniczych, Warszawa, Zakład Lotniskowy

krzysztof.blacha@itwl.pl

\section{Agata Kowalewska}

Mgr inż.

Instytut Techniczny Wojsk Lotniczych, Warszawa, Zakład Lotniskowy agata.kowalewska@itwl.pl

\section{Pawel Iwanowski}

Mgr inż.

Instytut Techniczny Wojsk Lotniczych, Warszawa, Zakład Lotniskowy

pawel.iwanowski@itwl.pl

DOI: $10.35117 / A \_E N G \_18 \_12 \_04$

\section{Assessment of anti-skid properties of airfield pavements using devices for friction coefficient continuous measurement}

\begin{abstract}
The anti-skid properties of airfield pavements are one of the crucial factors impacting air traffic safety within the ground manoeuvring area. These values are evaluated directly through an analysis of the pavement macro- and microstructure, based on the friction coefficient measurement. The friction coefficient is a ratio between the pressure force of the wheel on the pavement and the friction force generated on their contact surface. Currently there are numerous devices for continuous measurement of the friction coefficient (Continuous Friction-Measuring Equipment - CFME), which in terms of their basic principle of operation, do not differ significantly from each other. CFME measure the pressure force exerted by the measuring wheel on the pavement and the friction forces on the wheelpavement contact surface. The ratio of these two values is the friction coefficient. Apart from the similarities, these devices also exhibit difference, important in terms of the obtained values. The differences in the type and size of the used measuring tyre, value of wheel skid relative to the pavement or the pressure in the tyre should be mentioned. The results obtained from the measurements taken with the devices might differ by up to several ten percent, therefore they should not be compared, as well as referenced to the same requirements. At the same time, each of the devices enables the determination of anti-skid conditions of the pavement relative to the requirements set out for a given device type, which allows for the classification of the pavement in this regard. Taking classification into account, it is possible to compare the results obtained from various measuring devices. The article presents an overview of the instruments used for continuous friction measurement on airfield pavements, at the same time discussing the ones used on Polish roads. The authors emphasize the requirements for pavements in terms of roughness, taking into account the type of the used device. Moreover, it presents the test procedure for device with no previously determined requirements, but a need to introduce them to the market.
\end{abstract}

Keywords: Anti-skid properties; Friction coefficient; CFME 


\section{Introduction}

Today, there is a huge emphasis on safety. It mainly stems from the high social costs entailed by occurring events. In the case of transport, one of the factors significantly impacting the safety are the anti-skid properties of pavements. All types of safety systems, starting with ABS, through all kinds of traction control, ending with advanced anti-skid systems make sense only when adequate contact between a tyre and a surface is ensured. The selection of a proper tyre or suspension configuration is of significant importance in terms of the vehicle. In terms of the pavement, these will include obtaining the highest possible anti-skid parameters through ensuring proper friction coefficient measured with standardized methods.

All around the world, there are numerous devices for continuous measurement of the friction coefficient Continuous Friction-Measuring Equipment - CFME). Several of those were approved for measuring the friction coefficient on Polish airfields, while only two can be used for the roads. For over 20 years, an SRT-3 measuring set has been used for measuring anti-skid properties within the national road network. A TWO device has also been approved for use in measuring campaigns since several years. Both devices have their advocates and opponents, while there are no known methods, which would enable approving further devices for measuring the friction coefficient on national roads. Currently, there is also no known authority, which would certify such devices.

An international document Doc. 9137 AN/898 Airport Services Manual - Part 2 Pavement Surface Conditions [4], issued by the International Civil Aviation Organization (ICAO) allows the use of new measuring devices, stating the criteria and procedure of a device certification process. The article is aimed at familiarizing the road-traffic environment with the course of action regarding new CFME devices in the course of a certification process.

\section{Overview of continuous friction-measuring equipment}

All around the world, there are numerous devices for continuous measurement of the friction coefficient (CFME). Some of them are used in Poland. Despite the fact that each of these devices measures the same parameter, their configuration impacts the obtained result. This chapter presents typical devices used for measuring the friction coefficient on airfield facilities and roads throughout Poland. [10]

\section{Airfield equipment}

The Polish defence standard NO-17-A501:2015 Airfield pavements - Roughness test [12] contains a list of CFME devices approved for use on Polish military facilities. The aforementioned standard sets out the requirements to be satisfied by a device and an indication of the possibility to use the devices mentioned in AC 150/5320-12C FAA [1], Doc. 9137 ICAO [4] and Attachment 14 ICAO [2]. The cited provision stipulates that also new devices can find their application, provided they meet specific requirements.

Table (Tab. 1) contains a list of devices referred to in the standard [12], along with measurement conditions and the requirements for airfield pavements.

Tab. 1: Requirements as per NO-17-A501:2015 Airfield pavements - Roughness test [12]

\begin{tabular}{|c|c|c|c|c|c|c|c|}
\hline \multirow{3}{*}{$\begin{array}{c}\text { Measuring } \\
\text { device }\end{array}$} & \multirow{2}{*}{\multicolumn{2}{|c|}{ Test tyre }} & \multirow{3}{*}{$\begin{array}{c}\text { Test } \\
\text { speed }\end{array}$} & \multirow{3}{*}{$\begin{array}{l}\text { Water film } \\
\text { thickness }\end{array}$} & \multicolumn{3}{|c|}{ Friction coefficient } \\
\hline & & & & & \multirow{2}{*}{$\begin{array}{l}\text { Design values for } \\
\text { new pavements }\end{array}$} & \multirow{2}{*}{$\begin{array}{c}\text { Values for } \\
\text { planning } \\
\text { remedial actions }\end{array}$} & \multirow{2}{*}{$\begin{array}{c}\text { Minimum } \\
\text { values (limit) }\end{array}$} \\
\hline & Type & Pressure & & & & & \\
\hline
\end{tabular}




\begin{tabular}{|c|c|c|c|c|c|c|c|}
\hline & & $\mathrm{kPa}$ & $\mathrm{km} / \mathrm{h}$ & $\mathrm{mm}$ & & & \\
\hline \multirow{2}{*}{$\begin{array}{c}\text { Trailer } \\
\text { Surface } \\
\text { Friction Tester } \\
\text { (ASFT) }\end{array}$} & B & 700 & 65 & 1.0 & 0.70 & 0.50 & 0.40 \\
\hline & B & 700 & 95 & 1.0 & 0.60 & 0.40 & 0.32 \\
\hline \multirow{2}{*}{$\begin{array}{c}\text { Trailer } \\
\text { Mu-meter }\end{array}$} & $\bar{A}$ & 870 & 65 & $\begin{array}{ll}1.0 \\
\end{array}$ & $\begin{array}{ll}0.72 \\
\end{array}$ & $\begin{array}{ll}0.52 \\
\end{array}$ & 0.42 \\
\hline & $\mathrm{A}$ & 70 & 95 & 1.0 & 0.66 & 0.38 & 0.26 \\
\hline \multirow{2}{*}{$\begin{array}{c}\text { Trailer } \\
\text { Skiddometer }\end{array}$} & $\overline{\mathrm{B}}$ & 210 & $\begin{array}{l}65 \\
55\end{array}$ & $\begin{array}{l}1.0 \\
\end{array}$ & 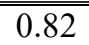 & $\begin{array}{c}0.60 \\
0.60\end{array}$ & 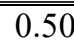 \\
\hline & B & 210 & 95 & 1.0 & 0.74 & 0.47 & 0.34 \\
\hline \multirow{2}{*}{$\begin{array}{c}\text { Trailer } \\
\text { RUNAR }\end{array}$} & $\mathrm{B}$ & 210 & 65 & $\begin{array}{l}1.0 \\
\end{array}$ & 0.69 & 0.52 & 0.45 \\
\hline & $B$ & 210 & 95 & 1.0 & 0.63 & 0.42 & 0.32 \\
\hline \multirow{2}{*}{$\begin{array}{c}\text { Vehicle } \\
\text { Airport Surface } \\
\text { Friction Tester } \\
(\text { ASFT) } \\
\end{array}$} & $\mathrm{B}$ & 700 & 65 & $\begin{array}{l}1.0 \\
\end{array}$ & $\begin{array}{c}0.70 \\
\end{array}$ & 0.50 & 0.40 \\
\hline & B & 700 & 95 & 1.0 & 0.60 & 0.40 & 0.32 \\
\hline \multirow{2}{*}{\begin{tabular}{c|} 
Vehicle \\
Surface \\
Friction Tester
\end{tabular}} & $\mathrm{B}$ & 210 & 65 & $\begin{array}{l}1.0 \\
\end{array}$ & 0.82 & 0.60 & 0.50 \\
\hline & $\mathrm{B}$ & 210 & 95 & 1.0 & 0.74 & 0.47 & 0.34 \\
\hline \multirow{2}{*}{$\begin{array}{c}\text { Vehicle } \\
\text { Runway } \\
\text { Friction Tester } \\
\end{array}$} & $\mathrm{B}$ & 210 & 65 & 1.0 & 0.82 & 0.60 & 0.50 \\
\hline & B & 210 & 95 & 1.0 & 0.74 & 0.54 & 0.41 \\
\hline \multirow{2}{*}{$\begin{array}{c}\text { Vehicle } \\
\text { TATRA } \\
\text { Friction Tester }\end{array}$} & $\bar{B}$ & 210 & 65 & 1.0 & 0.76 & 0.57 & 0.48 \\
\hline & B & 210 & 95 & 1.0 & 0.67 & 0.52 & 0.42 \\
\hline
\end{tabular}

The most popular friction coefficient measuring devices on Polish airfield facilities are the ASFT (Airport Surface Friction Testers) installed on a vehicle or an ASFT T-10 trailer, towed behind a vehicle (figure 1). Both devices enable continuous, linear measurement of the friction coefficient between an airfield pavement and a reference aircraft wheel at a speed of 65 or $95 \mathrm{~km} / \mathrm{h}$. They are equipped with a water tank and an airfield wetting mechanism, in order to reach the standard-specified water film with a thickness of not less than $1 \mathrm{~mm}$.

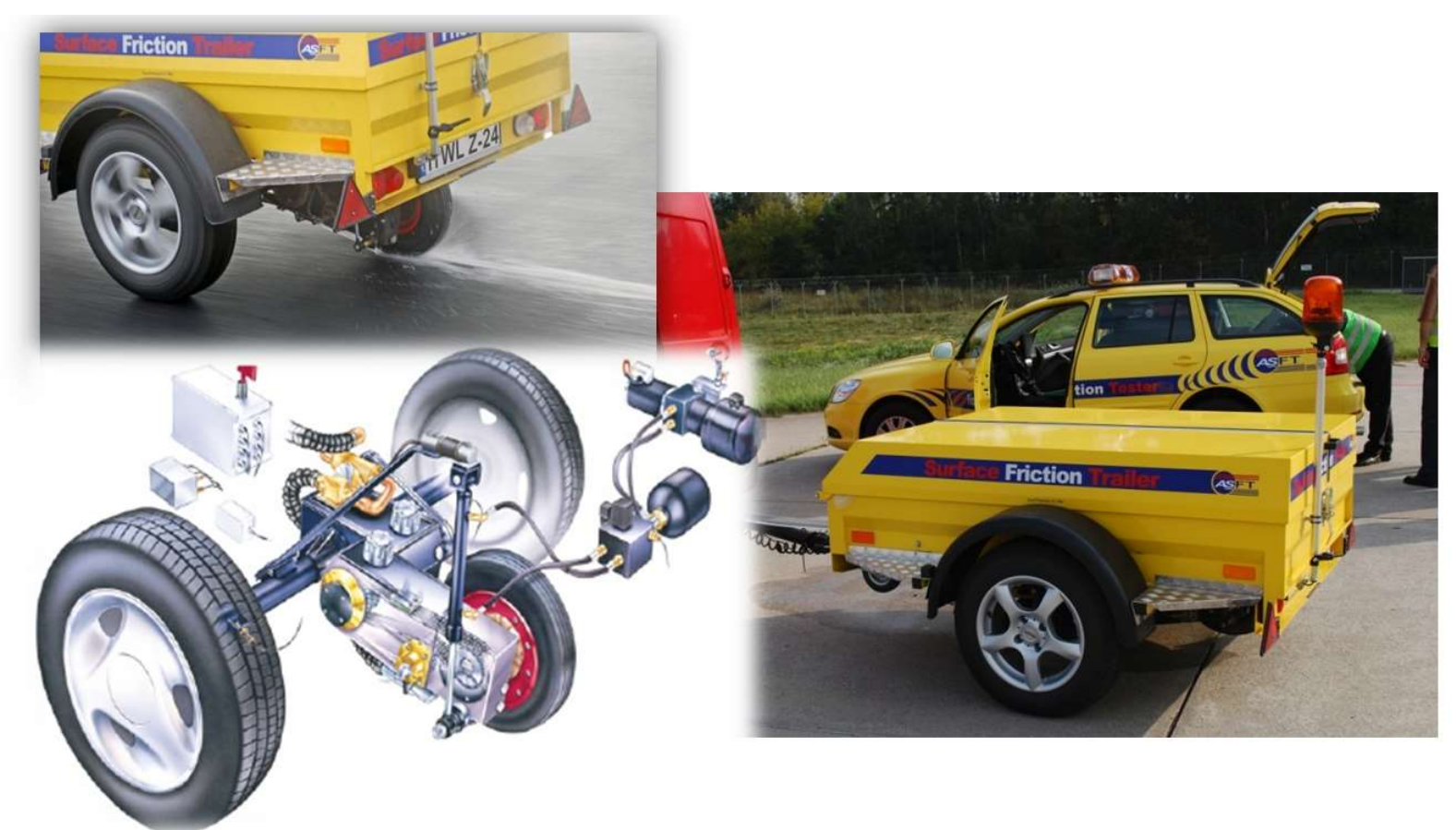

1. ASFT T-10 trailer belonging to the Department of Airfields at the Air Force Technical Institute (AFIT), ASFT vehicle in the background 
Smaller airfield functional elements, with their geometry preventing the measurement at a speed of 65 or $95 \mathrm{~km} / \mathrm{h}$, can be tested with a BVS-1 device or a manual, portable T2Go roughness tester (figure 2). Currently, the significance of the BVS-1 testing equipment decreased in favour of the T2Go. T2Go enables continuous measurement of the friction coefficient at low speeds, and the proper correlation between the results obtained with the use of an ASFT T-10 trailer enables a reference to the requirements contained within the aforementioned documents.
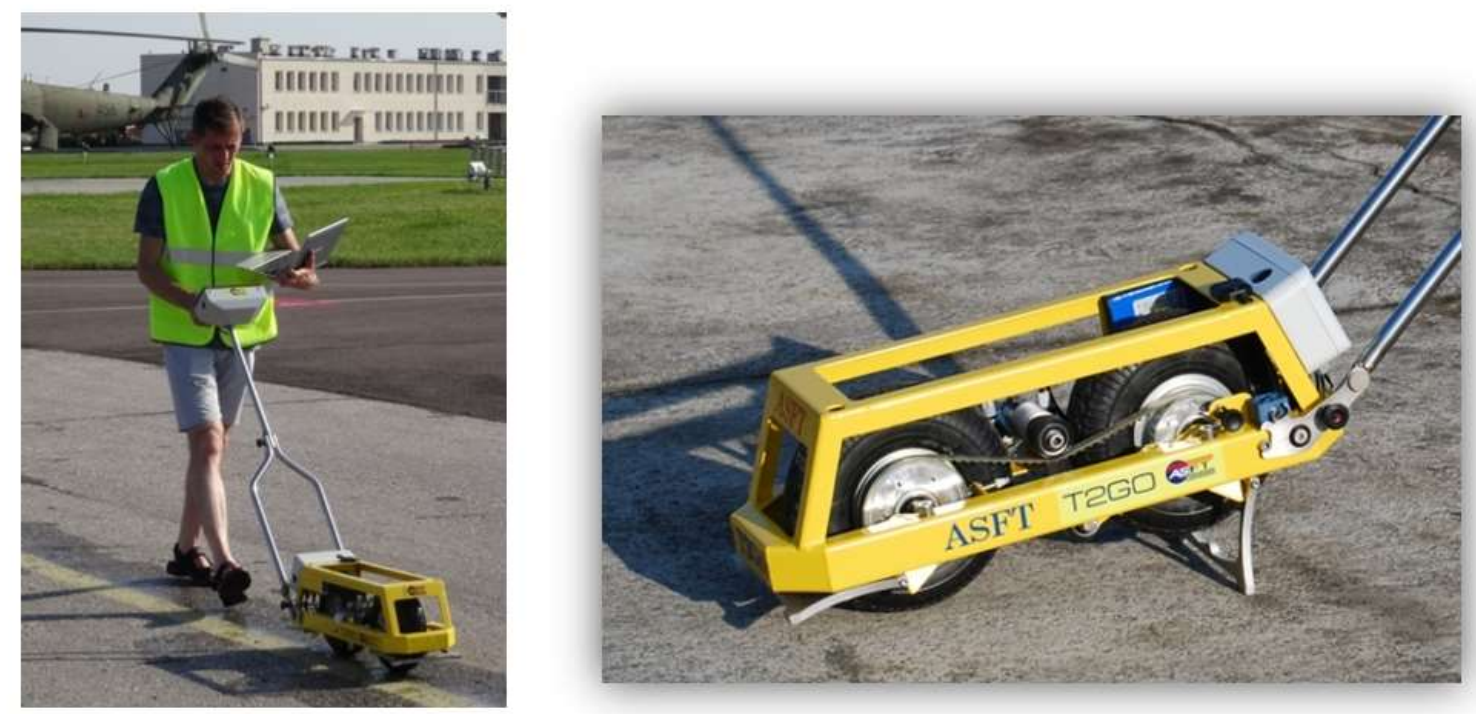

2. Friction coefficient measurement on the aircraft apron using a T2Go device belonging to the AFIT Department of Airfields

A spot measurement of the friction coefficient is possible with the use of a British pendulum. The results give a certain picture of the friction coefficient level characterizing a tested pavement. However, it only refers to a specific point, in contrast to the previously presented devices, which enable continuous measurement. Nowadays, a pendulum is used mainly for laboratory tests. It is only an additional comparison tool in the field, used with the results obtained via other methods. The criteria for the SRT index obtained from the British pendulum test are known only for road pavements.

Less frequent, although also present on our airfields are the devices of the Griptester MK2 type by Findlay Irvine (figure $\mathbf{3}$ left) and Skiddometer BV11 type by Moventor (figure 3 right). Both devices operate based on a similar principle as the ASFT T-10 enabling continuous friction coefficient measurement, whereas the Griptester MK2 is characterized by minor weight and dimensions. Each of the aforementioned devices is towed during the measurement by a wheeled vehicle and requires constant supply of water from a tank located on the vehicle. 

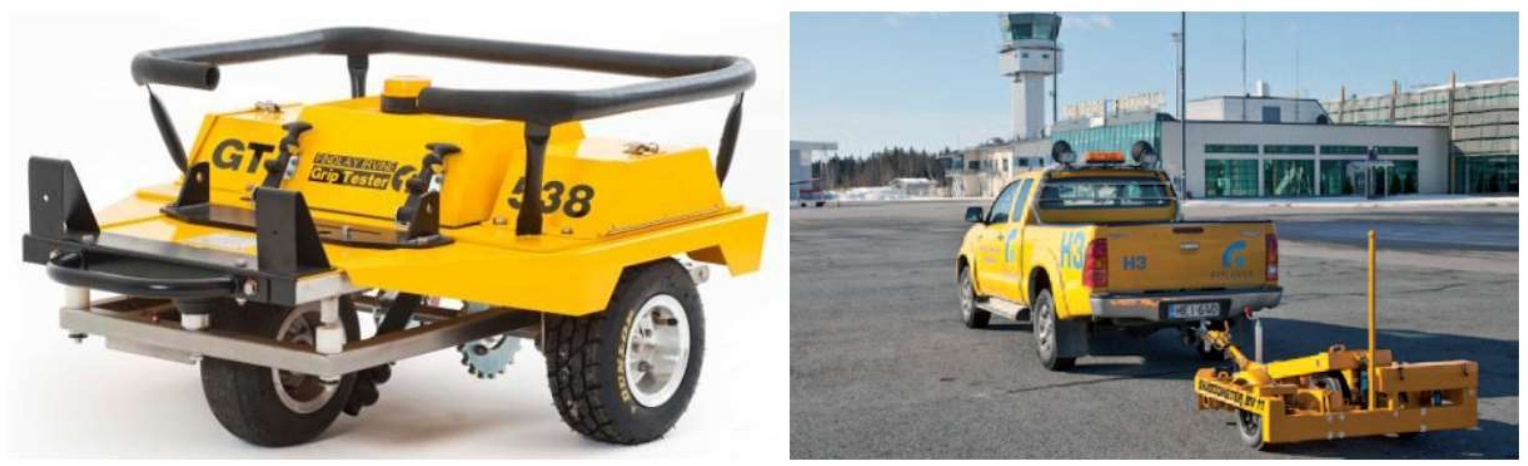

3. MK2 griptests (left) [12], BV11 Skiddometer (right) [13]

The MK2 Griptester uses a smooth 10inch tyre, compliant with the ASTM 1844 specification for the measurement. The size of the running wheels of the device is 10 inches, but they are retreaded. The pressure in the measuring tyre during the test is $140 \mathrm{kPa}$.

Two types of tyres can be used for measuring the friction coefficient with the use of a Skiddometer BV11. The first tyre type is a low-pressure ASTM tyre, and the second one is a smooth-treaded high-pressure T520 tyre. Both are compliant with the FAA and ICAO recommendation. The operating pressure in the measuring tyre is $210 \mathrm{kPa}$, while the wheel skid relative to the running wheels is $17 \%$.

\section{Road devices}

The road community has also numerous devices used in order to evaluate the anti-skid properties of the pavements. They enable measuring the friction coefficient at speeds from 30 to $120 \mathrm{~km} / \mathrm{h}$. Depending on the measurement method, we can distinguish the following groups of devices:

"side force" - the measuring wheel is rotated relative to the movement direction of the device by an angle of $7.5^{\circ}-20^{\circ}$, side friction forces are measured. This group contains, among others, SCRiM, SKM, Mu-Meter, Stradograph;

„fixed slip" - measuring wheel is positioned in accordance with the device movement direction, friction forces during a fixed slip are measured. This group includes, among others, DWW Trailer, Skidometer BV-8, GripTester, TWO;

„variable slip" - measuring wheel positioned in accordance with the device movement direction, variable slip friction forces are measured. This group is represented by ViaFriction;

„locked wheel” - measuring wheel is positioned in accordance with the device movement direction, friction forces with a completely locked wheel are measured (100\% slip). These devices include, among others, Adhera, Stuttgarter, Reibugsmesser, Pavement Friction Tester, SRT-3.

The SRT-3 and TWO devices were approved for use on Polish national roads by way of Regulation No. 34 by the General Director of National Roads and Motorways dated 30 April 2015 [13]. The SRT-3 device (figure 4) was constructed by the Road and Bridges Research Institute, whereas TWO (figure 5) is a foreign design. 


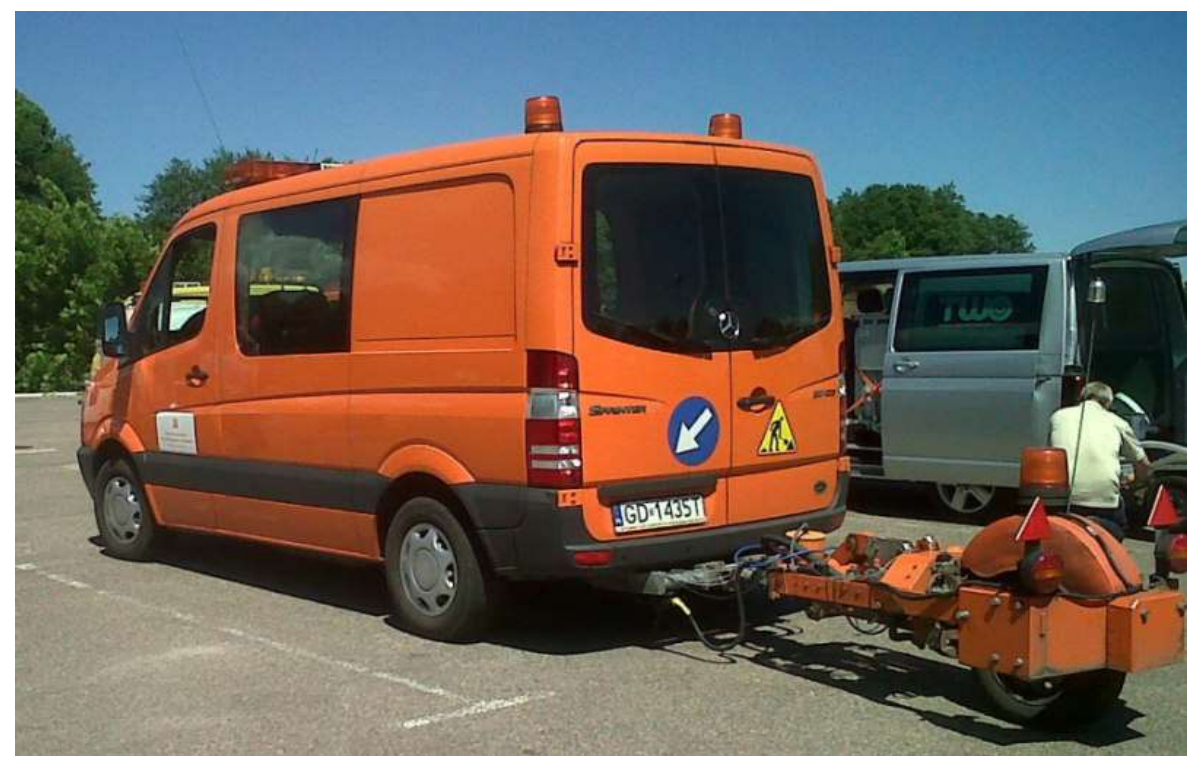

4. Measuring set SRT-3 [14]

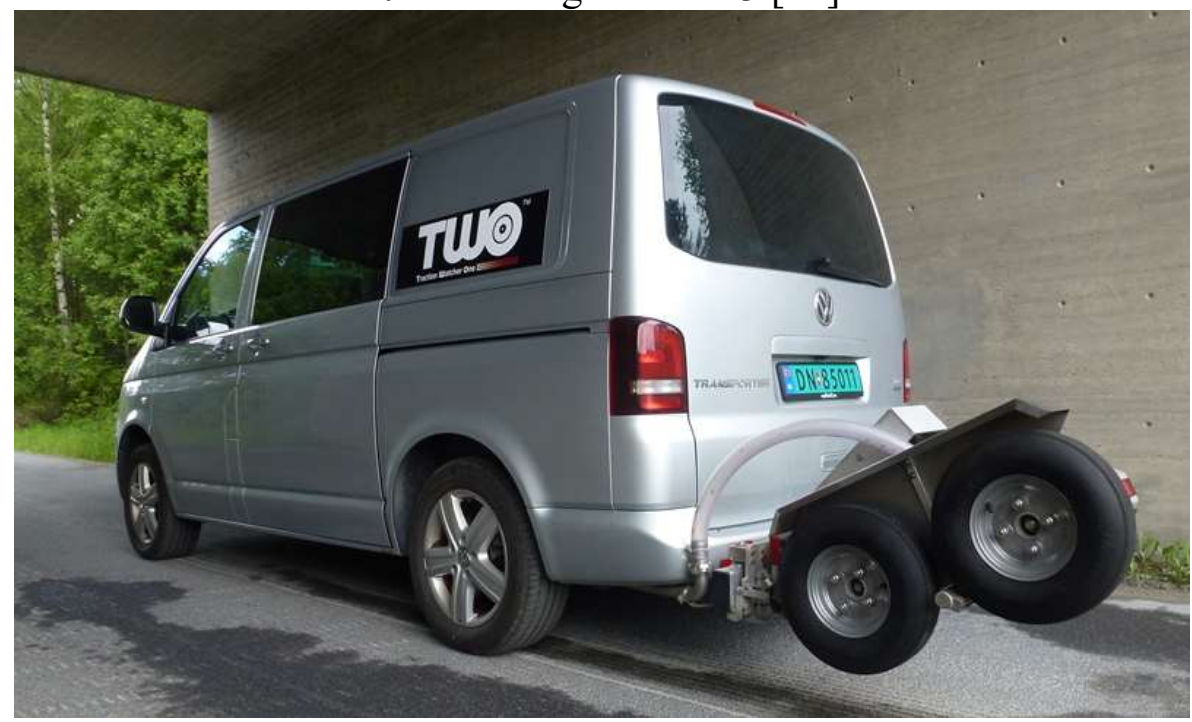

5. Measuring set TWO [15]

The SRT-3 measuring set, classified in the "locked wheel" group enables measuring the friction coefficient with a completely locked measuring wheel. A friction coefficient may be determined with two methods, i.e., either by measuring the braking torque generated on the measuring wheel or directly, through measuring the friction force on the tyre-road pavement contact surface. The discussed device enables also the measurement of the maximum friction coefficient value at a set measurement speed and the measurement of rolling resistance. The test can be performed at straight road section, as well as on curves.

A TWO set, classified in the "fixed slip" group, is used for continuous friction coefficient measurement on roads, as well as airfield facilities. The measuring device is fixed directly on the vehicle. It is equipped with two wheels interconnected via a chain, so that they move relative to each other, with a skid of $17.8 \%$. One wheel is a point of reference, while the second one is the measuring wheel. The measurement can be taken on a wet, as well as dry pavement, at a speed of 2 to $100 \mathrm{~km} / \mathrm{h}$. The volume of supplied water is controlled and enables creating a water film with a thickness of 0.1 to $1 \mathrm{~mm}$. A smooth or treaded tyre can be used for the measurement.

\section{Procedure in the case of new CFME devices}


An international document Doc. 9137 AN/898 ICAO [4] stipulates the criteria for new CFME devices, whereas attachment no. 3 [3] contains testing procedures for these devices. Hence, it is possible to introduce the use of devices other than the ones currently specified in normative documents, provided specific requirements are met.

\section{Requirements for new devices, as per Doc. 9137 AN/898}

In 1974 the basic technical and operating criteria for CFME devices (engineered by ICAO) were presented and recommended for measuring runway friction coefficient. In 1991, the requirements were revised and contained within the Airfield Services Guidebook Doc. 9137 AN/898 ICAO [4]. The criteria are aimed at standardizing the design parameters for new friction-measuring devices. Their task is also to ensure flexibility and enable adding future devices, not forgetting the technical progress in this field.

The basic requirements for new CFME devices in specified in the document are:

- measurement mode, which should enable continuous measurement during movement along the tested element;

- the option to calibrate the device in order to control result correctness. Even the slightest deviations during calibration may significantly impact a test result;

- measuring wheel braking mode - a measuring wheel shall remain in constant skid relative to the pavement (range from 10\% to 20\%), whereas in devices simulating side force, a set angle shall fall within a range from $5^{\circ}$ to $10^{\circ}$. Currently, the most common configuration used in Polish airfield is a wheel slip of ca. $15 \%$, without any side force;

- limiting excessive vibrations - the device shall be designed in such a manner, so as to mitigate and even eliminate amortized and non-amortized mass vibrations over an entire range of measurement speeds, particularly in relation to the measuring wheel. The vibrations impact the quality of the readings, as well as the control over the downforce of the wheel to the pavement;

- device stability during movement, including the ability to quickly leave a runway. The device shall not constitute a hazard for air traffic within the ground manoeuvring area, and at the request of an air traffic controller should be able to move to a safe zone as quickly as possible;

- the recorded friction coefficient should fall within a range from 0 to 1.0;

- the device shall ensure continuous recording of the runway friction coefficient value graph and provide its operator with an option to introduce any observations, as well as the recording date and time. Continuous recording is a simplification since CFME devices record the results at specific intervals; the distance covered by the device is so small relative to the measuring section distance that it can be deemed as a continuous measurement

- the device shall be able to repeat average friction coefficient measurement results within $\pm 0.03 \mu$, at a confidence level of $95.5 \%$ (or two standard deviations);

- the friction coefficient value shall be a ratio of the longitudinal friction force and the vertical measuring wheel load; in the case of a measurement simulating a side force, the friction coefficient shall correspond to the ration of the side force and the measuring wheel load. This requirement arises from the definition of the friction coefficient;

- the measurement speed range of a device should be 40 to $130 \mathrm{~km} / \mathrm{h}$; Despite the fact that the measurement range is wide, the standard speeds for measuring the friction coefficient are 65 and $95 \mathrm{~km} / \mathrm{h}$, with the other measurement speeds used for the purpose of the best possible determination of a correlation between the devices; 
- the device shall state an average friction coefficient value, at least for: the first $100 \mathrm{~m}$ of the runway, each $150 \mathrm{~m}$ of the measurement section and for each third of the runway length. The division of a runway into three sections is of particular importance for a pilot. During a landing approach, the pilot receives information about the friction coefficient on individual runway sections. It enables to know what conditions to expect after touchdown and how to manoeuvre the aircraft in the consecutive runway thirds;

- the measuring tyre should correspond to the types referred to in the document; the tyre cannot be replaced with another, unless it is verified to provide reliable and sound results. The standardization of measuring tyres is aimed at eliminating the impact of a used tyre on measurement conditions;

- the device must be able to take the measurements regardless of prevailing weather conditions. The friction coefficient on airfields is measured usually when it is suspected that the anti-skid properties of the pavement might have had deteriorated. Such a situation usually occurs as a result of adverse weather conditions. For this purpose, a device must be able to operate in all weather conditions;

- the maintenance of the device must be simple enough, to ensure safety during the measurements and handling;

- the device must be equipped with an automatic pavement sprinkling system, in order to provide a water film, at least $1 \mathrm{~mm}$ thick.

\section{New device testing procedure}

Attachment 3 [3] indicates four basic assumptions to be met in the course of testing a new CFME device:

- it should be determined whether device calibration methods applied by the manufacturer for measuring friction and water distribution systems for the device are satisfactory. The document does not stipulate specific requirements in this regard, which is why the assessment method used by the experts participating in the tests is extremely important;

- the measurements shall be conducted on at least four different pavement types, ensuring a broad range of friction coefficient results. In this case the document does not stipulate specific parameters to be met by a pavement as, e.g., its microand macrostructure, however, it is advisable to ensure selecting at least four pavement types, varying in terms of the friction coefficient values

- the measurements shall be conducted for at least two measurement speeds, i.e., 65 and $95 \mathrm{~km} / \mathrm{h}$. These are standard friction coefficient measurement speeds replicated in numerous documents, whereas in order to increase the set of results, one can take measurements also at different speeds. This will increase the amount of data and expand the result range;

- for each combination of measurement conditions, take the measurements in conditions of repeatability and, if possible, repeat the measurement in the same conditions, using a different certified CFME device, in order to verify result conformity.

Satisfying the aforementioned conditions will significantly ensure the repeatability of the results and enable monitoring the obtained results.

Despite the fact the document does not contain such a provision, it is worth ensuring cleanliness of a measured surface. The experiences of the authors show that the spread of results obtained on a soiled surface is large. Even certified devices may not be able to ensure repeatability at a level of $\pm 0.03 \mu$, and a confidence level of $95.5 \%$. In order to maintain 
appropriate surface cleanliness during the measurements, it is advisable to clean the pavement prior to each pass of a measuring device. The fastest option in the case of airfield is using airfield cleaner.

Further steps of the testing procedure for new CFME devices, according to Attachment $3[3]$, are as follows:

- checking the sub-assemblies of the device, the tyres and the data recording system in terms of correct configuration and operating conditions.

- calibrating the device as per the manufacturer's manual and saving the results.

- checking the water distribution system in terms of conformity of the volume of distributed water with the assumptions, and whether the water is supplied correctly by the measuring wheel at various speeds. The document does not define the check procedure. In practice, the length and width of a water footprint formed during the water footprint measurement is measured, and based on water loss in the device, the thickness of the water film formed in front on the wheel is determined.

- repeating the first three steps for the second certified CFME device used for result correlation, should it be used.

- if more than one device is used for the tests, determine the sequence of using these devices in the course of the passes and follow this sequence throughout the entire duration of the tests. It is important because for correlation purposes, the results from individual passes of measuring devices are compared. Despite the fact that it is not indicated in the document, make sure that the time between the passes of compared devices is as short as possible.

- making two or three test passes over the assumed pavement with each of the CFME devices, in order to stabilize the friction coefficient for a wet pavement and achieve acceptable repeatability, at a level of $\pm 0,03$. If the acceptable repeatability level for two passes with a similar speed is not achieved, check the measuring and data recording system, in order to detect irregularities. If necessary, correct any irregularities and recalibrate the device before restarting the tests.

- for each analysed speed, make at least 6 measurement passes for each device, for each of at least 4 pavement types. Naturally, the probability of correct device assessment increases along with increasing number of measurements.

- for each of the selected pavements, take the measurements for at least two measurement speeds - 65 and $95 \mathrm{~km} / \mathrm{h}$. Other measurement speeds will enable a more thorough determination of the dependency of a friction coefficient on the speed.

- analysing recorded data in order to determine the accuracy, repeatability and result conformity for each pavement and measurement speed.

- for the purposes of a comparison with friction coefficients obtained for a wet pavement, conduct two dry tests for each pavement and at similar measurement speeds, to the ones for a wet pavement.

- re-calibrating the devices as per the manufacturer's guidelines at the end of the tests and recording the results. The values obtained in the course of the calibration shall be similar to those from before the tests. If they are not, identify the cause and, if necessary, repeat the tests.

- developing graphs for the relation between the friction coefficient and the speed for each pavement. When using more than one device, plot the graphs for each of the devices on the same chart.

- determining the linear relationship and the friction coefficient for each case. The values shall be shown by each graph. 
- preparing a list of the main parameters of the conducted tests, including: test date, number of test passes, measurement time, pavement type, measurement speed, measurement direction, water film depth, average friction coefficient values.

- creating copies of historic test data, general notes, weather conditions and other observations, in order to submit to a proper certification authority. Usually, the documents are submitted to ICAO, which checks the correctness of the procedure and approves a device. The Civil Aviation Authority is the body in Poland, which can approve a device for use in domestic airfields.

The document recommends taking photos or making videos in the course of the tests, however, it is not obligatory. Experience shows that it is an important operation, facilitating the restoration of a device testing process.

\section{Practical application of the Procedure}

The presented test procedure for new continuous friction-measuring devices is not a dead document. Many of the devices had been certified as per the assumptions. Some of them, such as ViaFriction, are also used in the case of roads.

Devices are tested according to the presented procedure also in our domestic market. A very good example is a continuous friction-measuring device named CSR (Continuous Skid Resistance). The authors performed the tests of the aforementioned device as per the procedure in Attachment no. 3 [7]. The test assumptions were as follows:

- two measurement speeds - 65 and $95 \mathrm{~km} / \mathrm{h}$,

- measuring wheel skid value - $15 \%$,

- six different pavement types,

- four seasons (various weather conditions),

- wet and dry measurement,

- 10 passes in each of the measurement series,

- measurement series conducted under conditions of repeatability.

A total of almost 1000 measurement results in various measurement conditions were obtained. This enabled reliable estimation of the measurement repeatability of the tested device. Repeatability at a satisfactory level, not exceeding the value of Procedure assumptions was obtained.

At the same time, measurements with a reference device, in the same conditions were taken. A certified ASFT T-10 trailer was used as a reference device. This enabled the determination of a correlation between both devices.

Figure 6 presents a correlation graph, which is a fragment of a broader analysis. The graph relates to the comparison of the friction coefficient results obtained with the use of ASFT T10 to the friction coefficient results during a CSR measurement. The measurements were taken in the Summer, at a speed of $65 \mathrm{~km} / \mathrm{h}$ in wet conditions (i.e., with a water film of a ca. $1 \mathrm{~mm}$ thickness). An r-Pearson ratio at a satisfactory level of 0.86 was obtained. The regression strip determined for a confidence level of 0.95 is relatively narrow, while the spread of results around the regression line is satisfactory. 


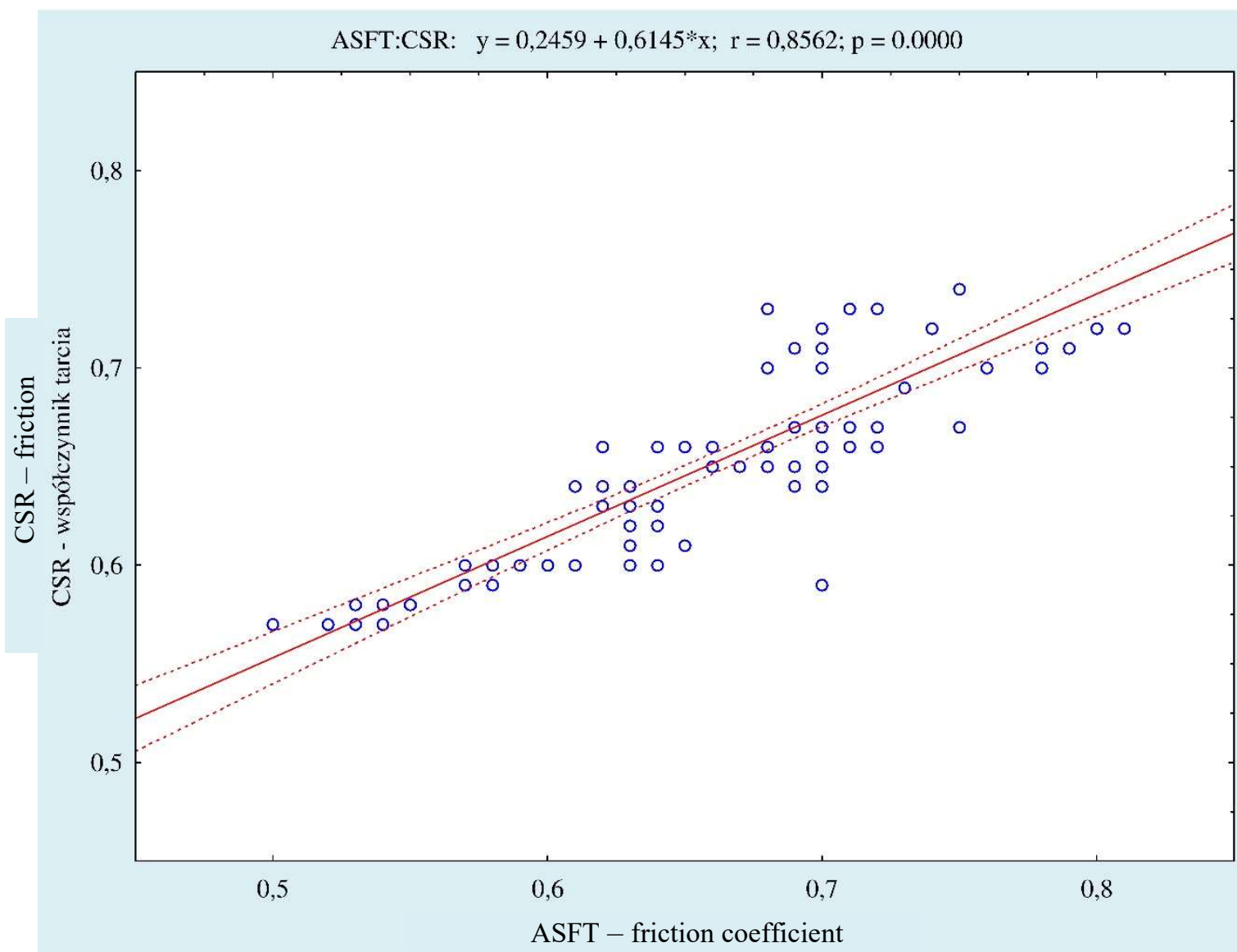

6. Correlation chart for the friction coefficient results obtained with CSR and ASFT T-10 devices

The title area of the graph also contains a regression equation, based on which it is possibly to easily relate the results obtained with the CRS device to the ones obtained with ASFT T-10. As a consequence of such a transformation, we can relate to the requirements set out for pavement testing in terms of their anti-skid properties.

\section{Conclusions}

The spectrum of globally available continuous friction-measuring equipment is very broad. There are many devices of this type, with new ones appearing every now and then. One of the factors which favour this situation is ensuring appropriate anti-skid conditions on road and airfield pavement through monitoring them and rapidly responding in the event of identified irregularities. This is aimed at ensuring the safety of road and airfield users.

The Polish defence standard [12], based on international documents, specifies a list of devices that can be used to determine the friction coefficient on airfield functional elements. The list includes eight most popular devices, with several of them used by the maintenance services of Polish airfield facilities. The standard also provides for the use of two alternative devices (BVS-1 and ASFT T2Go), if the geometric dimensions of an element do not enable using standard test equipment.

The national road standard is the SRT-3 manufactured by IBDiM (Road and Bridge Research Institute), normally used by the General Directorate for National Roads and Motorways. Besides, a TWO device can be used in measuring campaigns, as per regulation [13].

The aviation environment is not shut to devices currently indicated in normative documents and leaves a possibility of introducing new CFME devices for the tests. Document 
Doc. $9137 \mathrm{AN} / 898$ [4] is quite thorough in describing the procedure in such a case. It contains the requirements for new devices and their testing procedure referred to in this article. Attachment 3 [3] to the aforementioned document stipulates subsequent steps, and states the test conditions, basic assumptions, requirements in terms of result interpretation and the correct test documentation.

The article is aimed at providing the road community with a testing procedure for a new CFME device during its certification on airfield facilities and the possibilities of introducing new measuring instruments on the list of devices approved by national and international aviation authorities.

The method for testing a new continuous friction coefficient measuring device presented in the article shows that the Procedure discussed in the article is not a dead document and is used not only all over the World but also in Poland.

The authors bring up the issue of a possibility to adapt the presented method for application by the road traffic community in order to approve alternative device for measuring the anti-skid properties of road pavements.

\section{Source materials}

[1] AC 150/5320-12C FAA Measurement, Construction, and Maintenance of Skid Resistant Airport Pavement Surfaces

[2] Annex 14 to the Convention on International Civil Aviation, Airfields - Volume I Engineering and operation of airfields

[3] Appendix 3 NASA Certification Test Procedure for New Continuous FrictionMeasuring Equipment Used at Airport Facilities

[4] Doc. 9137 AN/898 Airport Services Manual - Part 2 - Pavement Surface Conditions,

[5] http://www.asft.se, September 2018

[6] http://www.docplayer.pl, September 2018

[7] http://www.griptester.us, September 2018

[8] http://www.moventor.com, September 2018

[9] http://www.two-friction.com, September 2018

[10] Iwanowski P., Blacha K., Wesołowski M., Review of modern methods for continuous friction measurement on airfield pavements, IOP Conf. Series: Materials Science and Engineering, 2018, volume 356

[11] J.W. Hall, K.L. Smith, L. Titus-Glover, J.C. Wambold, T.J. Yager, Z. Rado, Guide for pavement friction, Contractor's final report for NCHRP Project, 2009

[12] NO-17-A501:2015 Airport pavements - Friction testing,

[13] Ordinance no. 34 of the General Director of National Roads and Motorways of 30 April 2015

[14] W. Gardziejczyk, M. Wasilewska, P. Gierasimiuk, M. Motylewicz, Ocena właściwości przeciwpoślizgowych nawierzchni drogowych przy wykorzystaniu urzadzeń two, ctm $i$ dft [Assessment of road pavement anti-skid properties using two, $\mathrm{ctm}$ and $\mathrm{dft}$ devices], journal of civil engineering, environment and architecture, 2016

[15] W. Gardziejczyk, M. Wasilewska, P. Gierasimiuk, M. Motylewicz, Przeglad urzadzeń do oceny właściwości przeciwpoślizgowych nawierzchni drogowych [Overview of devices intended for assessing the anti-skid properties of road pavements], VIII Techniczne dni drogowe, Białystok 2015 